\section{Assessment of lipid and}

\section{hematological profile among blood donors in European Gaza Hospital,}

\section{Palestine}

\author{
Ahmad M Tabash ${ }^{1}$, Wesam M Afana ${ }^{1}$, Abdrabbou M Elregeb ${ }^{1}$, \\ Sameer Abu Eid ${ }^{1}$ and Ayman M Abu Mustafa ${ }^{2 *}$ \\ ${ }^{1}$ European Gaza Hospital, Ministry of Health, Gaza Strip, Palestine \\ ${ }^{2}$ Palestine College of Nursing, Khan Younis, Gaza Strip, Palestine
}

\section{Abstract}

Background: There is an important shortage of blood in the greatest blood banks worldwide to meet up with requirements for numerous medical interventions. Limited studies have associated regular blood donation to the lowering of lipid function parameters. Assessing the lipid function is a classical method of evaluating an individual's risk for coronary heart disease.

Objective: The general goal of the study is to determine lipid and hematological profile among blood donors in European Gaza Hospital, Palestine.

Materials and Methods: This study was a case-control study that involved 120 male, 40 of whom were regular blood donors (study group), 40 first time donors and 40 non- donors (control group) aged between 18-60 years. A volume of $5 \mathrm{ml}$ venous blood was drawn from each fasting participant into a dry biochemistry screw-capped tube. This was allowed to clot and the serum was used to determine total cholesterol (TC), triglycerides, High-density lipoprotein cholesterol (HDL-C), Low-density lipoprotein cholesterol (HDL-C), while HDL-C/ LDL-C and TC/LDL ratio were calculated by using the following formula. Anthropometric parameters (weight, height) of donors were measured using standard protocol. The height (in meter), weight (in kilogram) were used to calculate the body mass index (BMI) using the following formula. $\mathrm{BMI}=$ weight $(\mathrm{kg}) /$ (height in meter) ${ }^{2}$ and blood was collected from each participant in EDTA (for hematocrit, ESR). Three groups were matched for age and BMI. Data were analyzed using SPSS version 23 . Chi-square $\left(\chi^{2}\right)$ was used to compare the relationship between categorical variables, ANOVA was used to measure the difference between means. Data were summarized using tables, pie charts, histograms. A P-value $<0.05$ was considered to be statistically significant for all tests conducted.

Results: The mean total cholesterol $(169 \pm 10.85 \mathrm{mg} / \mathrm{dl})$, triglycerides $(116 \pm 9.73 \mathrm{mg} /$ dl), HDL $(54 \pm 2.5 \mathrm{mg} / \mathrm{dl}), \mathrm{LDL}(92 \pm 11.4 \mathrm{mg} / \mathrm{dl}), \mathrm{LDL} / \mathrm{HDL}$ ratio $(1.73 \pm 0.25)$ and TC/HDL ratio $(3.16 \pm 0.26)$ were lower in the regular blood donors than the first time donors $(198 \pm 10.13$, $179 \pm 5.82,42.33 \pm 1.6,120 \pm 11.2,2.85 \pm 0.36,4.7 \pm 0.40)$ and non- donors $(202 \pm 10.19,180 \pm 12.68$, $41.75 \pm 1.4,125 \pm 11.7,2.99 \pm 0.33,4.86 \pm 0.32)$ respectively and statistically significant $(P<$ $0.05)$. The mean ESR $(6.63 \pm 0.87 \mathrm{~mm} / \mathrm{hr})$ was lower statistically significant in the regular blood donors than the first time donors $(7.40 \pm 1.17)$ and non- donors $(7.60 \pm 1.48)$ respectively $(\mathrm{P}<$ $0.05)$. The mean HCT $(42.98 \pm 0.86 \%)$ was lower statistically significant in the regular blood donors than the first time donors $(44.63 \pm 0.90)$ and non- donors $(44.75 \pm 0.74, \mathrm{P}<0.05)$.

Conclusion: Regular donors have reduced risk of developing coronary heart disease as reflected by the low total cholesterol, triglycerides, LDL-c, LDL-c/HDL-c ratio, TC/HDL-c ratio and HCT and high HDL. BMI in regular donor was less than the donor for the first time and did not donate, but did not reach the statistical significance. Also in our study regular donors have reduced risk of developing inflammation as reflected by low ESR.

\section{More Information \\ Submitted: 06 July 2019 \\ Approved: 15 July 2019 \\ Published: 16 July 2019}

How to cite this article: Tabash AM, Afana WM, Elregeb AM, Abu Eid S, Abu Mustafa AM. Assessment of lipid and hematological profile among blood donors in European Gaza Hospital, Palestine. J Cardiol Cardiovasc Med. 2019; 4 073-079.

doi: 10.29328/journal.jccm.1001043

Copyright: @ 2019 Tabash AM, et al. This is an open access article distributed under the Creative Commons Attribution License, which permits unrestricted use, distribution, and reproduction in any medium, provided the original work is properly cited

Keywords: Lipid and hematological profile; Blood donors; European gaza hospital; Palestine

ISSN: 2575-0143

Check for updates 


\section{Introduction}

Blood transfusion is an important life- saving therapy to numerous who have experienced road accidents, maternal hemorrhage, anemia, different surgical procedures and a number of other medical and surgical conditions [1]. Blood derives from blood donors defined as "individuals who donates either whole blood or blood products for transfusion" who give a global rate of 112.5 million blood donations annually. Individuals donating blood may be regular blood donors or replacement donors as required by a member of their own family or friends [2].

The availability of blood still remains low to meet the elevated demand however wide efforts and an amount of blood donation programs. The best rate for maintaining a country's stock of blood and blood products at a suitable level can be maintained if $3-5 \%$ of the people donate blood each year according to the world health organization WHO. Unfortunately, $83 \%$ of the global population who live in developing countries have access to only $40 \%$ of blood supplied, and this blood in $60 \%$ of cases is come from paid or replacement blood donors more than from regular reducerisk donors.3

The lipid profile is a group of blood tests to evaluate the serum concentrations of lipoproteins, essentially TC, HDL-c, low-density lipoprotein cholesterol LDL-c, very-low-density lipoprotein cholesterol (VLDL-c), HDL-c, and triglycerides (TG) [4].

It is known that lipid dysfunction is related to cardiovascular disease (CVD), its diagnosis in puberty can reduce the chances of future complications, because a variation in lifestyle to healthier habits can be the greatest prevention [5]. In addition, a study that investigated the effects of blood donation observed that donating blood every 6 weeks reduced the oxidation of low-density lipoprotein (LDL), which is related to the development of atherosclerosis [6].

Body Mass Index (BMI) is an equation used to compute an individual's body fat content based on the weight-height ratio. BMI moreover controls for age and gender as well. Elevated BMI can be an indication of too much excess body fat, while reduces BMI can be an indication of too little body fat. The elevated a person's BMI, the greater their chances of developing certain negative health conditions, like heart disease, high blood pressure, and diabetes [7].

Packed cell volume (hematocrit) and body mass index assessment are important factors related to the etiology of certain disease; cardiovascular disease especially hypertension increased the risk for type 2 diabetes mellitus [8]. The commercial and voluntary blood donors differed significantly $(\mathrm{p}<0.05)$ in ESR, total protein, hematocrit, and BMI [9].
In the Gaza strip, there is no published study to investigate assessment of lipid profile, body mass index, erythrocyte sedimentation rate and hematocrit of status blood donors in European Gaza Hospital. This study has highlighted a great benefit to donors continuously.

\section{Materials and Methods}

\section{Study population and Experimental design}

Study design and samples: The present study is a descriptive case-control study. A total of 120 male who were matched for age, employment status, marital status, and education were recorded in the study. According to status of donations within the previous year, the male blood donors were divided into three groups: group I (regular donation those who have donated blood at 3 to 4 times in a year for at least two consecutive years), group II (first time donors consisted of men who were registered as new blood donors without any prior donations. and group III (non-donors) with 40, 40 and 40 people in each group, respectively. The study was conducted in the main public hospital: European Gaza Hospital in Khanyounis. The study was carried out during the period of October 2018 to February 2019.

\section{Inclusion criteria}

Inclusion criteria were accepted blood donors between aged 18-60 years who had donated blood at least two times in 12 months, at least first-time mains new blood donors without any prior donations and non-donors.

\section{Exclusion criteria}

Exclusion criteria were donors with a history of smoke use, hypertension, diabetes mellitus, a cardiovascular disease, less than 18 years and more than 60 years.

\section{Ethical considerations and permissions}

Consent form to participate in the study was obtained from the ministry of health and participants and freely participates in the study. Every participant had been provided with a full explanation of the intended study. Also, assurance of voluntary participation was maintained.

\section{Data collection}

An interview was used for filling in questionnaires. All interviews were conducted face to face by the researchers.

\section{Blood collection}

All blood samples were collected in a lavender top tube (EDTA) and serum was taken from participants and sent to the laboratory within 2 hours to tested lipid profile. EDTA tube was collected and tested quickly for HCT and ESR. The hemolysed sample is rejected, and sample tubes were allowed to reach room temperature $\left(15-30^{\circ} \mathrm{C}\right)$ before performing the assay. Anthropometric parameters (weight, height) of 
donors were measured using standard protocol. The height (in meter), weight (in kilogram) were used to calculate the body mass index $\left(\mathrm{kg} / \mathrm{m}^{2}\right)$ using the following formula. BMI= weight $(\mathrm{kg}) /$ (height in meter) ${ }^{2}$. Hematocrit was performed on all samples using cell dyne 1800 (Germany) for analysis [10]. ESR estimation was done without preservation within 1hour using standard methods.

Serum total cholesterol was determined quantitatively using DiaSys reagent kits, Serum triglyceride was determined quantitatively using DiaSys reagent kits [11], Serum HDL-C was determined quantitatively using DiaSys reagent kits while LDL-c was calculated using the Fridewald equation as follows:

LDL-C $=$ TC - HDL-C-TG [12].

All procedures were carried out as per the instruction manual of the test kits.

All analyses were done using Mindray BA88Aspectrophotometer.

Expected Values for total cholesterol: Desirable less than $200 \mathrm{mg} / \mathrm{dl}$, borderline $200-240 \mathrm{mg} / \mathrm{dl}$ and high risk more than $240 \mathrm{mg} / \mathrm{dl}$

Expected Values for triglyceride: Desirable: $<200 \mathrm{mg} /$ dl (fasting), borderline high: $200-400 \mathrm{mg} / \mathrm{dL}$ and elevated > $400 \mathrm{mg} / \mathrm{dl}$

Expected Values for HDL-C:>35 mg/dl

Expected Values for LDL-C:Desirable $130 \mathrm{mg} / \mathrm{dl}$, borderline high risk 130-160 mg/dL and high risk $>160 \mathrm{mg} / \mathrm{dL}$

LDL/HDL index ( $\geq 3.0$ ), TC/HDL index ( $\geq 4.5$ ) [13].

\section{Statistical analysis}

Data were analyzed using SPSS version 20. Chi-square $\left(\chi^{2}\right)$ and ANOVA were used where necessary to compare the relationship between categorical variables, the student t-test was used to measure the difference between means. Data were summarized using tables, pie charts, histograms. A P-value $<0.05$ was considered to be statistically significant for all tests conducted.

\section{Results}

\section{Socio-demographic characteristics of the study popu- lation}

Table 1 illustrated the socio-demographic characteristics of study populations. Three groups regular donors, first donors, and non-donors were matched in socio-demographic characteristics studied (age, BMI, employment status and marital status). regarding the age group, $50 \%, 42.5 \%$ and $45.0 \%$ from regular donors, first donors and non-donors respectively at age $18-28$ years, $27.5 \%$ from regular donors, first donors and non-donors at age 29-39 years, 20\% from regular donors, first donors and non-donors at age 40-50years while $2.5 \%, 10 \%$ and $7.5 \%$ from regular donors, first donors and non-donors respectively at age 51-61 years. $\mathrm{P}$-value $=0.96$ which indicated no significant differences among groups. Concerning employment status, 20\%, 17.5\% and $20 \%$ from regular donors, first donors, and non-donors respectively were working while $80 \%, 82.5 \%$ and $80 \%$ from regular donors, first donors and non-donors respectively were not working $(\mathrm{P}$-value $=1.000)$. Furthermore, $45 \%$ from regular donors, first donors, and non-donors respectively are single while $55 \%$ from regular donors, first donors, and nondonors respectively are married (P-value $=1.000)$. Moreover, $35 \%, 37.5 \%$ and $40 \%$ from regular donors, first donors and non-donors respectively are secondary education while $25 \%, 22.5 \%$ and $17.5 \%$ from regular donors, first donors and non-donors respectively are undergraduate while $40 \%, 40 \%$ and $45.5 \%$ from regular donors, first donors and non-donors respectively are graduate (P-value $=0.963$ ). These results indicated statistically no significant differences among groups in socio-demographic characteristics which reflected good matching between among groups.

Table 1: Socio-demographic characteristics of study populations.

\begin{tabular}{|c|c|c|c|c|c|c|c|c|c|}
\hline \multirow{2}{*}{ Variable } & \multirow{2}{*}{ Category } & \multicolumn{2}{|c|}{ Regular donors } & \multicolumn{2}{|c|}{ First donors } & \multicolumn{2}{|c|}{ Non-donors } & \multirow{2}{*}{$x^{2}$} & \multirow{2}{*}{ p-value } \\
\hline & & No. & $\%$ & No. & $\%$ & No. & $\%$ & & \\
\hline \multirow{4}{*}{ Age (years) } & $18-28$ & 20 & 50 & 17 & 42.5 & 18 & 45.0 & \multirow{4}{*}{2.000} & \multirow{4}{*}{0.926} \\
\hline & $29-39$ & 11 & 27.5 & 11 & 27.5 & 11 & 27.5 & & \\
\hline & $40-50$ & 8 & 20 & 8 & 20 & 8 & 20 & & \\
\hline & $51-61$ & 1 & 2.5 & 4 & 10 & 3 & 7.5 & & \\
\hline \multirow{2}{*}{ Employment status } & Working & 8 & 20 & 7 & 17.5 & 8 & 20 & \multirow{2}{*}{0.000} & \multirow{2}{*}{1.0} \\
\hline & Not working & 32 & 80 & 33 & 82.5 & 32 & 80 & & \\
\hline \multirow[t]{2}{*}{ Marital status } & Single & 18 & 45 & 18 & 45 & 18 & 45 & \multirow{2}{*}{0.000 .0} & \multirow{2}{*}{1.0} \\
\hline & Married & 22 & 55 & 22 & 55 & 22 & 55 & & \\
\hline \multirow{3}{*}{ Education } & Secondary & 14 & 35 & 15 & 37.5 & 16 & 40 & \multirow{3}{*}{0.785} & \multirow{3}{*}{0.963} \\
\hline & Undergraduate & 10 & 25 & 9 & 22.5 & 7 & 17.5 & & \\
\hline & Graduate & 16 & 40 & 16 & 40 & 17 & 42.5 & & \\
\hline
\end{tabular}

The significance of difference was checked by chi-square test (compare study group and control), significant at $P \leq 0.05$ 


\section{Anthropometric parameters}

Table 2 shows that there were no statistically significant differences in weight, height, and BMI between three studied groups $(\mathrm{P}>0.05)$, this indicates that status of donors no affects the level of lipid profile and hematological parameters.

\section{Lipid profile parameters}

Table 2 shows that there were statistically significant differences in cholesterol level related to the status of donors $(\mathrm{F}=125.72, \mathrm{P}=0.001)$, which means that the status of donors affects the level of cholesterol. Concerning triglyceride level, there were statistically significant differences in triglyceride level related to the status of donors $(\mathrm{F}=568.48, \mathrm{P}=0.001)$, which means that the status of donors affects the level of triglyceride furthermore, there were statistically significant differences in HDL level related to the status of donors ( $\mathrm{F}=$ $486.15, \mathrm{P}=0.001)$, which means that the status of donors affects the level of HDL moreover, there were statistically significant differences in LDL level related to status of donors $(\mathrm{F}=96, \mathrm{P}=0.001)$, which means that status of donors affects the level of LDL also there were statistically significant differences in LDL/HDL ratio related to status of donors $(\mathrm{F}=$ 192.77, $\mathrm{P}=0.001$ ), which means that status of donors affects the level of LDL/HDL ratio while there were statistically significant differences in TC/HDL ratio related to status of donors $(\mathrm{F}=323.33, \mathrm{P}=0.001)$, which means that status of donors affects the level of TC/HDL ratio (Table 3 ).

Table 2.1 shows clarification post hoc Scheffe test was performed and it shows that those who have regulatory donors had lower levels of cholesterol, triglyceride, LDL, LDL/ HDL, and total cholesterol/ HDL compared to non-donors and first time donors, while those who have regulatory donors had higher levels of HDL compared to non-donors and first time donors.

\section{Hematological parameters}

Table 4 shows that there were statistically significant differences in height related to the status of donors $(F=7.363$, $\mathrm{P}=0.001$ ), which means that the status of donors affects the level of ESR. Also, there were statistically significant differences in HCT related to the status of donors $(F=56.118$, $\mathrm{P}=0.001$ ), which means that the status of donors affects the level of HCT.

Table 4.1 shows clarification post hoc Scheffe test was performed and it shows that those who have regulatory donors had lower levels of ESR compared to non-donors and first-time donors. Also, it shows that those who have regulatory donors had lower levels of HCTcompared to nondonors and first-time donors.

\section{Discussion}

A total of 120 male subjects were recorded for the study,
Table 2: Differences in status of donors according to anthropometric parameters.

\begin{tabular}{|c|c|c|c|c|c|c|}
\hline Variable & Status of donors groups & $\mathbf{N}$ & Mean & SD & $\mathbf{F}$ & $P$ value \\
\hline \multirow{4}{*}{ Weight (kg) } & Regular donors & 40 & 78.10 & 8.83 & \multirow{3}{*}{0.171} & \multirow{3}{*}{0.843} \\
\hline & First-time donors & 40 & 78.75 & 8.85 & & \\
\hline & Non donors & 40 & 79.28 & 9.35 & & \\
\hline & Regular donors & 40 & 1.80 & 0.06 & \multirow{3}{*}{0.083} & \multirow{3}{*}{0.92} \\
\hline \multirow[t]{2}{*}{ Height(m) } & First-time donors & 40 & 1.79 & 0.06 & & \\
\hline & Non donors & 40 & 1.8 & 0.05 & & \\
\hline \multirow{3}{*}{$\mathrm{BMI}\left(\mathrm{kg} / \mathrm{m}^{2}\right)$} & Regular donors & 40 & 24.07 & 1.45 & \multirow{3}{*}{1.071} & \multirow{3}{*}{0.346} \\
\hline & First-time donors & 40 & 1.41 & 24.38 & & \\
\hline & Non donors & 40 & 1.63 & 24.56 & & \\
\hline
\end{tabular}

BMl; body mass index. Values expressed as mean \pm standard deviation (SD) of 120 participants. The significance of difference was checked by ANOVA test (compare all case and control), significant at $P \leq 0.05$

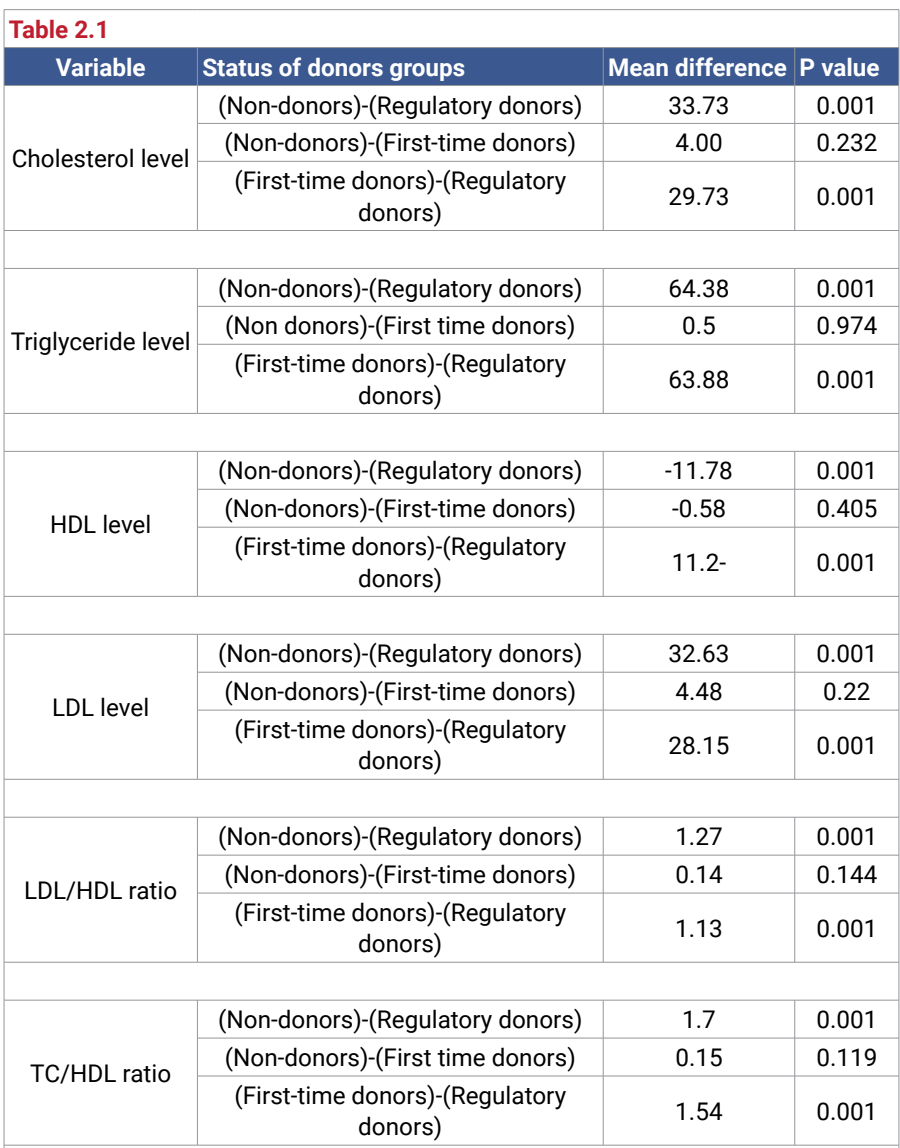

The significance of difference was checked by ANOVA test (compare all case and control), significant at $\mathrm{P} \leq 0.05$.

surprisingly none female volunteer donor was recorded in the study. It may not be that women do not want to donate blood, perhaps they want to do, but most of them are not qualified to donate due to very low hemoglobin levels or suffer from various types of anemia $[14,15]$.

\section{Socio-demographic characteristics of study participants}

The present study demonstrated that there was no association between socio-demographic characteristics and status of donors which included age groups, employment status, marital status, and education. This indicates the sociodemographic characteristics not affected results as confiding. So there was matching between cases and controls in most these characteristics. Our result agreement with Uche et al. 


\begin{tabular}{|c|c|c|c|c|c|c|}
\hline Variable & Status of donors groups & $\mathbf{N}$ & Mean & SD & $\mathbf{F}$ & $P$ value \\
\hline \multirow{3}{*}{$\begin{array}{c}\text { Cholesterol } \\
\text { level }\end{array}$} & Regular donors & 40 & 169 & 10.85 & \multirow{3}{*}{125.72} & \multirow{3}{*}{0.001} \\
\hline & First-time donors & 40 & 198 & 10.13 & & \\
\hline & Non donors & 40 & 202 & 10.19 & & \\
\hline & & & & & & \\
\hline \multirow{3}{*}{$\begin{array}{l}\text { Triglyceride } \\
\text { level }\end{array}$} & Regular donors & 40 & 9.73 & 116 & \multirow{3}{*}{568.48} & \multirow{3}{*}{0.001} \\
\hline & First-time donors & 40 & 5.82 & 179 & & \\
\hline & Non donors & 40 & 12.68 & 180 & & \\
\hline & & & & & & \\
\hline \multirow{3}{*}{ HDL level } & Regular donors & 40 & 2.5 & 54 & \multirow{3}{*}{486.15} & \multirow{3}{*}{0.001} \\
\hline & First-time donors & 40 & 1.6 & 42.33 & & \\
\hline & Non donors & 40 & 1.4 & 41.75 & & \\
\hline & & & & & & \\
\hline \multirow{3}{*}{ LDL level } & Regular donors & 40 & 11.4 & 92 & \multirow{3}{*}{96} & \multirow{3}{*}{0.001} \\
\hline & First-time donors & 40 & 11.2 & 120 & & \\
\hline & Non donors & 40 & 11.7 & 125 & & \\
\hline & & & & & & \\
\hline \multirow{3}{*}{$\begin{array}{l}\text { LDL/HDL } \\
\text { ratio }\end{array}$} & Regular donors & 40 & 0.247 & 1.73 & \multirow{3}{*}{192.77} & \multirow{3}{*}{0.001} \\
\hline & First-time donors & 40 & 0.36 & 2.85 & & \\
\hline & Non donors & 40 & 0.33 & 2.99 & & \\
\hline \multirow{3}{*}{$\begin{array}{c}\mathrm{TC} / \mathrm{HDL} \\
\text { ratio }\end{array}$} & Regular donors & 40 & 0.26 & 3.16 & \multirow{3}{*}{323.33} & \multirow{3}{*}{0.001} \\
\hline & First-time donors & 40 & 0.4 & 4.7 & & \\
\hline & Non donors & 40 & 0.32 & 4.86 & & \\
\hline
\end{tabular}

HDL-c; high density lipoprotein, LDL; low density lipoprotein, TC; total cholesterol. Values expressed as mean \pm standard deviation (SD) of 120 participants.

Table 4: Differences in status of donors according to Hematological parameters.

\begin{tabular}{|c|c|c|c|c|c|c|}
\hline Variable & $\begin{array}{c}\text { Status of donors } \\
\text { groups }\end{array}$ & $\mathrm{N}$ & Mean & SD & $\mathrm{F}$ & $P$ value \\
\hline \multirow{3}{*}{$\begin{array}{c}\mathrm{ESR}(\mathrm{mm} / \\
\mathrm{hr})\end{array}$} & 0.87 & 6.63 & 40 & Regular donors & \multirow{3}{*}{7.363} & \multirow{3}{*}{0.001} \\
\hline & 1.17 & 7.4 & 40 & $\begin{array}{l}\text { First-time } \\
\text { donors }\end{array}$ & & \\
\hline & 1.48 & 7.6 & 40 & Non donors & & \\
\hline & & & & & & \\
\hline \multirow{3}{*}{ НCT(\%) } & 0.86 & 42.98 & 40 & Regular donors & \multirow{3}{*}{56.118} & \multirow{3}{*}{0.001} \\
\hline & 0.9 & 44.63 & 40 & $\begin{array}{c}\text { First-time } \\
\text { donors }\end{array}$ & & \\
\hline & 0.74 & 44.75 & 40 & Non donors & & \\
\hline
\end{tabular}

ESR; Erythrocyte Sedimentation Rate, HCT; hematocrit. Values expressed as mean \pm standard deviation (SD) of 120 participants. The significance of difference was checked by ANOVA test (compare all case and control), significant at $\mathrm{P} \leq 0.05$.

\begin{tabular}{|c|c|c|c|}
\hline Table 4.1: Post-hoc Scheffe test. \\
\hline \multirow{3}{*}{ Variable } & $\begin{array}{c}\text { Status of donors groups } \\
\text { ESR(mm/hr) }\end{array}$ & Mean difference & P value \\
\cline { 2 - 4 } & (Non-donors)-(Regulatory donors) & 0.975 & 0.018 \\
\cline { 2 - 4 } & $\begin{array}{c}\text { (Non donors)-(First time donors) } \\
\text { (First-time donors)-(Regulatory } \\
\text { donors) }\end{array}$ & 0.2 & 0.758 \\
\hline \multirow{3}{*}{ HCT (\%) } & $\begin{array}{c}\mid c 775 \\
\text { (Non-donors)-(Regulatory donors) }\end{array}$ & 0.001 \\
\cline { 2 - 4 } & (Non-donors)-(First-time donors) & 0.125 & 0.974 \\
\cline { 2 - 4 } & $\begin{array}{r}\text { (First-time donors)-(Regulatory } \\
\text { donors) }\end{array}$ & 1.65 & 0.001 \\
\hline
\end{tabular}

The significance of difference was checked by ANOVA test (compare all case and control), significant at $P \leq 0.050$

in 2013 who found that there was no significant difference in the mean age between the two groups $(\mathrm{P}=0.461)$ [16].

In contrast to the above reports, the previous study found a significant increase in TC, LDL and TG levels as we move from a lower age group to a higher age group [17]. It is possible this study different in study design.

\section{Lipid profile levels of the different study groups}

Voluntary blood donors have been identified in different studies as a group with a reduced risk of cardiovascular disease when compared with irregular donors or first-time donors.

In the present study was evaluated regularly with nondonors and the first time donor. This study showed that there were statistically significant differences in cholesterol level $(\mathrm{P}=0.001)$ when compared with non-donors and firsttime donors. Also In our study, it showed that those who have regulatory donors had also lower levels of triglyceride and statistical significant $(\mathrm{P}=0.001)$ when compared with nondonors and first-time donors. It showed that those who have regulatory donors had higher levels of HDL and statistically significant $(\mathrm{P}=0.001)$ compared to non-donors and first-time donors and LDL $(\mathrm{P}=0.000)$ in the study group when compared with the control group. Available texts recommend that LDL/ HDL values exceeding three are associated with elevated risk for cardiovascular events. 18 In our study showed that those who have regulatory donors had lower levels of LDL/ HDL ratio compared to non-donors and first-time donors. Also, it showed that those who have regulatory donors had lower levels of TC/HDL ratio compared to non-donors and first-time donors.

Similarly, Uche et al. found that a significantly lower total cholesterol $(\mathrm{P}=0.000)$ and LDL $(\mathrm{P}=0.000)$ in the study group compared with the control group. The triglyceride level was also lower in the study group but didn't reach significance $(\mathrm{P}$ $=0.119$ ). Contrary to our study showed that mean HDL level in the control group was significantly higher than in the study group $(\mathrm{P}=0.016)$ and also observed that $57 \%$ of the control population had a ratio of three or higher compared with $42 \%$ of the study population with a ratio of three or higher, but this difference did not reach significance. The failure to reach significance might be due to the study's small sample size. A bigger study with larger sample size is required [18].

Among the parameters, plasma LDL/high-density lipoprotein (HDL) ratio is a better indicator of risk for coronary heart disease than either plasma LDL or HDL alone [19]. Bharadwaj also showed that lipid profile had significantly healthier pattern among the recent donors as compared to the past donors. Also, it can be said that the recent donors had a significantly greater protective effect against CHD than the past donors through both the groups had a lipid profile range within the normal limits [20]. The previous study also showed that regular donors had lower mean total cholesterol, triglyceride, LDL, TC/HDL, and LDH/HDL compared to irregular donors. However, none of these reached statistical significance while mean HDL in the irregular blood donors was higher than that of regular blood donors did not reach statistical significance $(P=0.944)$ [21]. Further studies have borne out that blood donation may 
be beneficial by increasing the serum HDL concentration [6]. Fallara et al. found that total cholesterol decreased significantly in repeat donors when compared with the first time blood donors $(\mathrm{P}<0.05)$. Similarly, LDL and VLDL values were decreased significantly in repeat donors. High density lipoproteins and triglycerides values did not differ significantly when the two categories were compared [7].

Adediran et al. observed that decrease in TC has been associated with repeated donations; while LDL in regular donors was reported to be lower in regular donors than in first-time donors [21]. Our study is consistent with the previous study which showed that regular blood donors had lower plasma LDL level than the first-timers [22]. In contrast to the above reportsMasukaetal suggested that there was no difference in TC, HDL, LDL/HDL ratio and TC/HDL ratio of the participants. There was however an unexpected result with regular blood donors having a significantly higher average level of LDL than first-time donors. The difference in LDL might is attributed to the difference in age of donors. Firsttime donors are by their nature younger than active donors in Zimbabwe due to the criteria used for selecting donors [23]. In contrast to our study in the USA, it was shown that there is no significant association between blood donation and the risk of myocardial infarction [24].

\section{Anthropometric parameter of the different study groups}

In our study, the mean BMI for voluntary, first-time donors and non-donors were $24.07 \pm 1.45 \mathrm{~kg} / \mathrm{m}^{2}, 24.38 \pm 1.41 \mathrm{~kg} /$ $\mathrm{m}^{2}$ and $24.56 \pm 1.63 \mathrm{~kg} / \mathrm{m}^{2}$ respectively and there was no significant difference between regular donor with first-time donors and non-donors.

Fallara et al. found that BMI values in the first time donors were significantly higher than obtained in repeat donors $(\mathrm{P}<0.001)$. Thus, regular blood donation is beneficial to health because the lowering of plasma total cholesterol and LDL levels reduce the risk of developing cardiovascular diseases [7]. It was shown that phlebotomy will reduce body iron stores, lower blood pressure, and reduce the risk of developing hyperglycemia and cardiovascular diseases, characteristics most often associated with obesity [16].

In contrast to our stud, Getta et al. showed that BMI in regular donors was significantly higher than obtained in the first time donors $(\mathrm{P}<0.001)$ [22]. It is possible that most people with higher BMI, advanced age and low physical activity tend to show an unfavorable plasma lipid profile that may predispose them to cardiovascular diseases. Thus, obese people may have greater inclination to donate blood because of this benefits [25].

\section{Hematological parameters of the different study groups}

The erythrocyte sedimentation rate (ESR) is a physical phenomenon related to plasma viscosity and the number of red cells. Plasma viscosity, or more precisely the albumin/ globulin ratio, is altered in an acute phase reaction and is probably the most significant factor affecting. An additional factor which influences ESR is serum fibrinogen level [26].

In our study, the mean ESR for voluntary, first-time donors and non-donors were $6.63 \pm 0.868(\mathrm{~mm} / \mathrm{hr}), 7.40 \pm 1.172(\mathrm{~mm} /$ $\mathrm{hr})$ and $7.60 \pm 1.482(\mathrm{~mm} / \mathrm{hr})$ respectively and there was a significant difference between regular donor with first-time donors and non-donors.

In the previous study, the mean ESR for voluntary and Commercial were $6.79 \pm 3.80 \mathrm{~mm} / \mathrm{hr}$ and $12.33 \pm 8.39(\mathrm{~mm} /$ hr) respectively and there was a significant difference between regular donor and Commercial donor [10].

The HCT, also known as packed cell volume or erythrocyte volume fraction, is the volume percentage (\%) of red blood cells in blood and functions as a major determinant of blood viscosity, blood pressure, venous return, cardiac output, and platelet adhesiveness [27,28]. In our study, the mean HCT for voluntary, first-time donors and non-donors were $42.98 \pm 0.86 \%, 44.63 \pm 0.90 \%$, and $44.75 \pm 0.74 \%$ respectively and there was a significant difference between regular donor with first-time donors and non-donors. Elevated HCT levels might function significantly increasing Hb levels and promote the increase of blood viscosity; thus dynamically altering the blood rheological parameters, followed by weakening of microvascular perfusion and the acceleration of the thrombus formation. Therefore, it was biologically plausible that HCT might be one of the major pathological mediators of CVD (Skretteberg et al., 2010).

In the previous study, the mean HCT for voluntary and Commercialwere $38.86 \pm 2.20 \%$ and $36.68 \pm 4.05 \%$ respectively and there was a significant difference between regular donor and Commercial donors [10].

\section{Conclusion}

The mean levels of cholesterol, triglyceride, LDL, LDL/ HDL ratio and TC/HDL ratio showed significant lower while HDL showed significantly higher in regular donor than in healthy controls. Moreover, the mean level of BMI observed a decrease in regular donor but did not reach statistical significance. Also, the mean levels of ESR and HCT found significant less in regular donor than in first-time donors and non- donors.

\section{References}

1. World Health Organization. Blood Safety and Availability, WHO Fact Sheet No. 279. Geneva: World Health Organization. 2014.

2. World Health Organization. Regional status report on blood safety and availability 2016 (No. WHO-EM/LAB/392/E). World Health Organization. Regional Office for the Eastern Mediterranean. 2017.

3. Shidam UG, Lakshminarayanan S, Saurabh S, Roy G. Knowledge and attitude regarding blood donation in rural Puducherry, India. Natl J Community Med. 6: 64-68. 2015. 
4. Faludi AA, Izar MCO, Saraiva JFK, Chacra APM, Bianco HT, et al. Atualização da diretriz brasileira de dislipidemias e prevenção da aterosclerose-2017. Arq Bras Cardiol. 2017; 109: 1-76. PubMed: https://www.ncbi.nlm.nih.gov/pubmed/28813069

5. Medeiros $Y$, Pinheiro L, Rodrigues $P$. Analysis on the lipid profile of adolescents from a municipality of sertao paraibano. Temas em Saúde. 2016; 16: 45-48.

6. van Jaarsveld H, Pool GF. Beneficial effects of blood donation on high density lipoprotein concentration and the oxidative potential of low density lipoprotein. Atherosclerosis. 2002; 161: 395-402. PubMed: PubMed: https://www.ncbi.nlm.nih.gov/pubmed/11888523

7. Fallara J. Association Between the Body Mass Index and School Attendance Among K-3rd Public School Children. 2018.

8. Tamariz LJ, Young JH, Pankow JS, Yeh HC, Schmidt MI, et al. Blood viscosity and hematocrit as risk factors for type 2 diabetes mellitus: the atherosclerosis risk in communities (ARIC) study. Am J Epidemiol. 2008; 168: 1153-1160. PubMed: https://www.ncbi.nlm.nih.gov/ pubmed/18931370

9. Felix CE, Ogodo ND, Ngozi AA. Evaluation of body mass index, hematocrit, erythrocyte sedimentation rate and total protein in voluntary and commercial blood donors in Nigeria: Advocating for simultaneous screening for nutritional status. Int $\mathrm{J}$ Blood Transfus Immunohematol. 2017; 7: 26-32.

10. Heymann MA, Payne BD, Hoffman JI, Rudolph AM. Blood flow measurements with radionuclide-labeled particles. Progress in cardiovascular diseases. 1977; 20: 55-79.

11. Bakker AJ, Mücke M. Gammopathy interference in clinical chemistry assays: mechanisms, detection and prevention. Clin Chem Lab Med. 2007; 45: 1240-1243. PubMed: https://www.ncbi.nlm.nih.gov/ pubmed/17635066

12. Young DS. Effects of drugs on clinical laboratory tests. AACC press. 2000.

13. Millán J, Pintó $X$, Muñoz A, Zúñiga $M$, Rubiés-Prat $J$, et al. Lipoprotein ratios: physiological significance and clinical usefulness in cardiovascular prevention. Vasc Health Risk Manag. 2009; 5: 757765. PubMed: https://www.ncbi.nlm.nih.gov/pubmed/19774217

14. Girija PL. Anemia among women and children of India. Anc Sci Life. 2008; 28: 33. PubMed: https://www.ncbi.nlm.nih.gov/pmc/articles/ PMC3336343/

15. Bentley ME, Griffiths PL. The burden of anemia among women in India. Eur J Clin Nutr. 2003; 57: 52-60.

16. El Uche, A Adediran, OD Damulak, TA Adeyemo, AA Akinbami, et al.. Lipid profile of regular blood donors. J Blood Med. 2013; 4: 39-42. PubMed: https://www.ncbi.nlm.nih.gov/pmc/articles/PMC3663474/
17. Clement ANJ, Vincent VSV, Shey ND, Afoni BE, Marcelin NN. A CrossSectional Study on the Evaluation of the Lipid Profile of Regular Blood Donors in the Buea Regional Hospital, Cameroon. Cardiology and Cardiovascular Research. 2017; 1: 76-83.

18. Wiklund RA, Stein HD, Rosenbaum SH. Activities of daily living and cardiovascular complications following elective, noncardiac surgery. Yale J Biol Med. 2001; 74: 75-87. PubMed: https://www.ncbi.nlm.nih. gov/pmc/articles/PMC2588693/

19. Bharadwaj R. A study of lipid profiles among male voluntary blood donors in Chennai city. Indian J Community Med. 2005; 30: 16-17.

20. Panagiotakos DB, Toutouzas PK. Importance of LDL/HDL cholesterol ratio as a predictor for coronary heart disease events in patients with heterozygous familial hypercholesterolaemia: a 15-year follow-up (1987-2002). Current medical research and opinion. 2003; 19: 89-94.

21. Adediran A, Adeyemo TA, Akanmu AS. Lipid profiles of regular blood donor. J Blood Medicine. 2013; 4: 39-42.

22. Getta HA, Ahmad HA, Rahman HS, Ahmed GA, Abdullah R. Medical and laboratory assessment for regular blood donors in sulaimani Blood Bank, Iraq. Patient preference and adherence 2018; 12: 939-944. PubMed: https://www.ncbi.nlm.nih.gov/pmc/articles/PMC5987750/

23. Masuka TJ, Muswe R, Marange P, Zhou DT. Coronary Heart Disease Risk Profiles in Blood Donors at the National Blood Services. Zimbabwe Sch Bull. 2017; 3: 469-471.

24. Ascherio A, Rimm EB, Giovannucci E, Willett WC, Stampfer MJ. Blood donations and risk of coronary heart disease in men. Circulation. 2001; 103: 52-57. PubMed: https://www.ncbi.nlm.nih.gov/ pubmed/11136685

25. Kamhieh-Milz S, Kamhieh-Milz J, Tauchmann $Y$, Ostermann $T$, Shah $\mathrm{Y}$, et al. Regular blood donation may help in the management of hypertension: an observational study on 292 blood donors. Transfusion. 2016; 56: 637-644. PubMed: https://www.ncbi.nlm.nih. gov/pubmed/26643612

26. Siemons L, Ten Klooster PM, Vonkeman HE, van Riel PL, Glas CA, et al. How age and sex affect the erythrocyte sedimentation rate and C-reactive protein in early rheumatoid arthritis. BMC Musculoskelet Disord. 2014; 15: 368. PubMed: https://www.ncbi.nlm.nih.gov/ pubmed/25373740

27. Brooks AC, Guillaumin J, Cooper ES, Couto CG. Effects of hematocrit and red blood cell-independent viscosity on canine thromboelastographic tracings. Transfusion. 2014; 54: 727-734. PubMed: https://www.ncbi.nlm.nih.gov/pubmed/23901836

28. Nemeth $\mathrm{N}$, Alexy $\mathrm{T}$, Furka $\mathrm{A}$, Baskurt $\mathrm{OK}$, Meiselman $\mathrm{HJ}$, et al. Inter-species differences in hematocrit to blood viscosity ratio. Biorheology. 2009; 46: 155-165. PubMed: https://www.ncbi.nlm.nih. gov/pubmed/19458418 